\title{
Experience of sexuality after breast cancer: a qualitative study with women in rehabilitation ${ }^{1}$
}

\author{
Elisabeth Meloni Vieira² \\ Daniela Barsotti Santos ${ }^{3}$ \\ Manoel Antônio dos Santos ${ }^{4}$ \\ Alain Giami ${ }^{5}$
}

Objective: to comprehend the psychosocial and cultural repercussions of breast cancer and its treatment on the sexuality of women. Method: this is a qualitative study grounded in the Sexual Scripts Theory with the participation of 23 women who were interviewed and participated in focus groups discussion. Results: each category was related to a level of the sexual scripts. At the cultural scenario level a discourse on sexuality that includes definitions of sexual attractiveness and sexuality was highlighted. The interpersonal scripts level focused on the communication regarding sexuality established with the partner and with healthcare professionals category; and at the subjectivity scripts level the reports of improvement, deterioration and no change in the sexual life after cancer were analyzed. Conclusion: the experience of cancer involves cultural, relational, and subjective aspects that affect the sexual life, therefore, healthcare professionals should be aware of them to improve integral healthcare.

Descriptors: Breast Neoplasms; Sexuality; Interpersonal Relations; Oncologic Nursing; Qualitative Research.

\footnotetext{
${ }^{1}$ Paper extracted from doctoral dissertation "Sexuality and body image in women with breast cancer" presented to Programa Interunidades de Pós-graduação em Enfermagem, Escola de Enfermagem, Universidade de São Paulo, São Paulo, SP, Brazil and Escola de Enfermagem de Ribeirão Preto, Universidade de São Paulo, WHO Collaborating Centre for Nursing Research Development, Ribeirão Preto, SP, Brazil. Supported by Fundação de Amparo à Pesquisa do Estado de São Paulo (FAPESP), process \# 2009/50319-8.

${ }^{2}$ PhD, Associate Professor, Faculdade de Medicina de Ribeirão Preto, Universidade de São Paulo, Ribeirão Preto, SP, Brazil.

${ }^{3}$ Post-doctoral fellow, Faculdade de Medicina de Ribeirão Preto, Universidade de São Paulo, Ribeirão Preto, SP, Brazil. Scholarship holder from Conselho Nacional de Desenvolvimento Científico e Tecnológico (CNPq).

${ }^{4}$ PhD, Associate Professor, Departamento de Psicologia, Faculdade de Filosofia Ciências e Letras de Ribeirão Preto, Universidade de São Paulo, Ribeirão Preto, SP, Brazil.

${ }^{5} \mathrm{PhD}$, Research Director, Team Genre, Santé Sexuelle et reproductive, Centre de recherche en Epidémiologie e Santé des Populations, Institut National de la Santé et de la Recherche Médicale (INSERM-U1018), Le Kremlin-Bicêtre, France.
}

Corresponding Author: Elisabeth Meloni Vieira

Universidade de São Paulo. Faculdade de Medicina de Ribeirão Preto

Av. Bandeirantes, 3900

Bairro: Monte Alegre

CEP: 14049-900, Ribeirão Preto, SP, Brasi

E-mail: bmeloni@fmrp.usp.br
Copyright (c) 2014 Revista Latino-Americana de Enfermagem This is an Open Access article distributed under the terms of the Creative Commons Attribution Non-Commercial License (CC BY-NC).

This license lets others distribute, remix, tweak, and build upon your work non-commercially, and although their new works must also acknowledge you and be non-commercial, they don't have to license their derivative works on the same terms. 


\section{Introduction}

Breast cancer is configured as a worldwide public health problem. In Brazil, in 2008, 458,000 deaths were caused by this type of neoplasm(1), being the second most frequent type of cancer among women. It was estimated that in 2012, there were 53,000 new cases in the country ${ }^{(2)}$. The treatment, in addition to breast surgery - conservative or not, includes chemotherapy, radiotherapy and endocrine therapy, which are aggressive and invasive therapeutic measures, with serious bodily consequences that affect the lives of women. Side effects of the treatment may compromise the well-being, causing nausea, vomiting, fatigue, alopecia, induced menopause, decreased vaginal lubrication, decreased sexual arousal, dyspareunia and anorgasmia. Accordingly, the physical, psychological and social effects of the treatment, as well as the body region affected, can have consequences on the sexuality ${ }^{(3)}$.

Cancer is a critical event that causes perplexity and fear of finitude, while simultaneously fostering concerns about the recovery and quality of the survival(4). Often the woman goes through a period of questioning and revision about how she has lived her life so far, with a reevaluation of beliefs and values. The literature also highlights concerns related to the body image ${ }^{(5)}$ and to the relationship with the partner(6), and apprehension about sexuality and the sexual life ${ }^{(7-9)}$. Sexuality is a psychosocial construct that includes biological, cultural, relational, and subjective aspects. It embraces all the physical and mental practices performed for the purpose of obtaining sexual pleasure from a person, either with oneself or with another; it integrates the personal identity and contributes to human reproduction. Furthermore, sexuality participates in an interplay between sex, corporeity, cultural rules, and gender throughout the individual and collective history ${ }^{(10)}$.

This study adopted the theoretical framework of Sexual Scripts, which includes the comprehension of sexuality from social scripts resulting from the adaptive demands of people to the social environment that are presented at three levels: the cultural scenarios, the interpersonal scenarios and the intrapsychic scenarios, which dynamically interact(11). The cultural scenarios are instructions for the collective life plan, and the interpersonal scenarios concern the social interaction. The adaptation and development of new scripts faced with the demands of the cultural and interpersonal scenarios lead the person to develop an internal rehearsal with alternative outcomes in a symbolic reorganization of reality at the intrapsychic scenarios level(11).

Studies that seek to comprehend the consequences of the treatments for breast cancer on the sexuality of women emphasize the relationship between the psychophysiological and hormonal aspects of the sexual function and the psychosocial aspects, such as the relationship with the partner and the anxiety and stress $^{(12-13)}$. The cultural aspects related to the experience of sexuality in breast cancer are less discussed. It can also be observed that sexuality is not usually a subject discussed by healthcare professionals with patients and their partners, as they fear sexualization of the care ${ }^{(14)}$. It is necessary that healthcare professionals, especially nurses, comprehend the sexuality of the woman after breast cancer, from the accompaniment during the period of diagnosis, treatment and recovery, so that they can provide better healthcare. This qualitative study aimed to comprehend the psychosocial and cultural repercussions of breast cancer and its treatment on the sexuality of women affected.

\section{Method}

The study was conducted in a city in the northeast of São Paulo state, with about 600,000 inhabitants and a strong economy due to commerce, service provision, agriculture, agribusiness, industry, and education. The data collection was carried out in a rehabilitation service for women after the diagnosis of breast cancer associated with the University where the study was performed. The research project was approved by the Research Ethics Committee (protocol No. 1074/2009) and all the participants signed the Terms of Free Prior Informed Consent, according to Resolution 196/96 of the National Health Council(15). To ensure the anonymity of the participants, the names presented in this study are fictitious. The performance of semi-structured interviews and focus groups was chosen, in which the scripts were developed based on the theoretical framework mentioned ${ }^{(11)}$. The data collection took place between September 2009 and December 2010. The combined use of distinct data collection strategies made it possible to acquire rich material for analysis, because, while the interview allowed access to the information that involved intimacy, the focus groups made it possible to obtain opinions on socially debated subjects(16).

A total of 23 women diagnosed with breast cancer who were attending a cancer rehabilitation service participated in the study. All the women were invited 
to participate in both the individual interviews and the focus groups. A total of 15 women were interviewed and two focus groups discussion were conducted, with five and seven individuals in each; four women were participants of both data collection strategies. The total number of participants was defined by the saturation of the themes related to the aim of the study. The data were recorded and fully transcribed, constituting the corpus of analysis. The socio-demographic data and information related to the diagnosis and treatment were collected with the participants, and from a consultation of the medical records.

The desire was to obtain a wide diversity of reports about sexuality in the context of breast cancer by giving priority to the psychosocial and cultural aspects involved in the experience. Obtaining this variability of experiences and opinions was only possible due to the inclusion of participants with different prognoses and therapeutic approaches. In this sense, it was decided to conduct a brief characterization of the participants and to include the time interval between the diagnosis and the data collection, as it is understood that the diagnosis of the disease itself brings questions and reflections about the sexuality of the woman.

As already mentioned, the sexual scripts theoretical framework adopted in this qualitative study guided the sexuality comprehension process and the analysis of the thematic content, as well as its interpretation(11). The material was coded with the aid of the NVivo 9 computer program, from thematic categories constructed by the researchers themselves. The data were triangulated to examine the convergent and divergent aspects among the thematic contents ${ }^{(16)}$. A certain level of sexual script (the cultural, interpersonal, and intrapsychic scenarios) was attributed to each analytic category, according to the dominant thematic content. The intrapsychic level was renamed as the subjectivity level(14).

\section{Results}

The 23 participants were between 36 and 76 years of age. Twenty women were in long-term affective relationships. The majority of the participants had children, declared themselves Catholic, had completed less than nine years of schooling, and were not pursuing paid professional activity. The diagnosis had occurred between 1992 and 2009. The time between the diagnosis and the data collection ranged from 10 months to 18 years. A total of 11 participants had undergone total mastectomies, five quadrantectomies and seven lumpectomies All of them underwent at least one (neo) adjuvant treatment.

The analytical categories that emerged from the corpus constructed from the individual interviews and the focus groups were grouped according to the three sexual script levels: Cultural, interpersonal, and subjectivity scenarios. In the cultural scenarios category a discourse was highlighted regarding sexuality marked by the traditional gender relationships in which feminine sexual attractiveness is an attribute which is highly valued and aspired to. Definitions were given of sexual attractiveness and beauty, composed of culturally valued standards and interspersed with subjective aspects. In this sense, the opinion of others was considered to be an important validation source of their own impressions. Some participants considered themselves to be beautiful, but not sexually attractive. For them, sexual attractiveness was related to body beauty, slimness and youth, whereas beauty referred to facial features and subjective characteristics such as kindness and friendliness. Others did not differentiate sexual attractiveness from beauty and considered themselves attractive even after the treatment. These reports refer to an idea of beauty that is available to women of all ages through the use of aesthetic treatments and clothing. Some reports expressed feelings of grief and devalorization, bought about by the post-treatment bodily changes, as they involved physical characteristics related to the culturally valued models of beauty and femininity.

Sexuality was conceptualized from the reports that wove a distinction between what sexual conduct is socially acceptable, based on traditional gender relationships characterized by a sexual double standard, where female sexual desire is denied and that of the male is naturalized and overvalued. The existence of an active female sexuality would be admitted only in the social role of the prostitute. Conversely, the male sexual desire is instinctive and urgent, since men would always be ready for sexual intercourse, as proof of their virility.

A difference between the "old times" and "modern times" was established. In the "old times" sex should only take place within the context of marriage, currently in the "modern times", there would be greater freedom for the woman to enjoy a sexual life. However, this behavior was criticized by some participants because this would create sexual relationships of a superficial and disposable character. Some stated that it is the duty of the wife to have sex with her husband whenever he desires. There were reports describing the use of the 
sexual practice as a servile obligation of the woman in the marriage, which was independent of her will and did not give her sexual pleasure. Otherwise, the man would need to placate his instinctive sexual desire with other women, seeking extramarital relationships. The wife would thus be threatened with losing her husband.

The experience of sexuality and sexual relations plays a key role in the field of human relationships, especially among women who were always competing with each other for the attention of a man. For this, it is necessary that the woman is always well "presented" and physically attractive, and willing to vary the sexual repertoire with the partner, since there would be strong competition in the affective-sexual market. If this is the fundamental role of female sexuality in a relationship, it can be considered that cancer and its treatments, which involve pronounced bodily modifications, configure the threat of abandonment by the husband as one of the most feared consequences for the women. Many of the participants stated that "the man leaves the sick woman". Interestingly, none of them went through this experience.

Other reports highlighted a concept of sexuality as important for the well-being of the woman. From this perspective, an unbalanced view is presented of the argument that places female sexuality as intrinsically passive, a past description, formerly belonging to the "old times".

Participant of focus group 1: [...] If there is no dialogue and kissing on the mouth, the marriage is finished. This is to live just sticking it out, to live out of obligation, right. [...] With a man you have to be sexy with him, understand? How are you going to go to bed with a man without passion? (Luana, 52 years, divorced and currently dating, cleaner).

Desire and feminine sexual pleasure were considered to be extremely important elements to liven up the sexual relationship. Sexual intercourse, which was not conducive to pleasure and an orgasm for the woman, was compared to the use of a toilet, as the partner would use the female body for simple discharge and obtaining satisfaction for his physiological needs. From this concept the sexual experience would best be enjoyed by the woman when dialogue and the companionship of the couple prevailed, since sexual desire in the woman would be less exuberant than in the man. This is because women have major concerns about the family, child care, household chores, and work; and would need caressing and a romantic climate for intercourse to be initiated.

In the interpersonal scenarios category communication about sexuality established with the partner and with healthcare professionals was highlighted. It was observed that the discourses on sexuality permeated the interactions that the participants established with the people surrounding them. Many partners became carers for the women during the treatment and provided emotional support and help for the practical issues of daily life. The concerns and difficulties that the treatments produced in the sexual life of the couple were themes that were discussed, particularly with regard to the reduction of desire, difficulty with vaginal lubrication, pain during intercourse, and reduction or absence of female orgasm.

Sexual problems of the partner, such as difficulties in arousal and erection, attributed to aging, were frequent subjects of conversation. Such difficulties of the partner were viewed with concern, as some participants expected men to always manifest intense sexual desire.

Interviewee: [...] then again I said to him: Funny, why is it that there are women that have a husband who is excited at our age, eh? [...] Then he said: Ah, I think it depends a lot on each person. I must have some problem, because it is not possible (Tatiana, 54 years, married, housewife).

There were reports of seeking advice from healthcare professionals with the aim of promoting the adaptation of the sexual life after breast cancer and dealing with the sexual difficulties of the partners. The incentive for the couple to seek assistance from healthcare professionals for solving such problems was mentioned.

The need was stressed for the woman and the family to be informed regarding the physical and psychological consequences of the treatments from the beginning, the woman especially needs to be informed about possible changes in the sexual life. One participant reported "step by step" instructions that she received from a physician for the resumption of sexual activity after the treatment.

Participant of focus group 2: [...] She explained to me: [...] pass one year without relations, it is going to hurt, everything. Then you will use a lubricant [...] You'll start making out. [...] you're going to hug, you're going to kiss. On another night, you will be stroking [...] until you reach the sexual part. [...] on one day it hurts, the other day less until you let yourself go. You will start making love (Rita, married, 54 years old, retired).

It can be noticed, from the reports that the advice given by the healthcare professionals was mostly prescriptive, without opening space for the dialogue and reflection of the women about their needs in the area of sexuality.

In the subjectivity category reports about the sexual life of the participants were highlighted. It was noticed that the concepts of sexuality intermediated by 
the culture and the interpersonal relationships revealed themselves by the way that the woman dealt with the unfolding of the treatments and its consequences on the sexual life. Despite reports about changes in sexual function, such as decreased desire, reduced arousal and vaginal lubrication, and anorgasmia and dyspareunia, which can be caused by the treatments, differing assessments of the sexual life were given. Some of the women reported an improved sexual life, others stated that it remained the same as before the illness, and some participants reported a worsening of the sexual life. Enrichment of the sexual life after breast cancer was justified by improvements in the loving relationship, with the expression of greater affective involvement from the companion.

Some reports referred to the change in attitude of the woman after having gone through a period of reflection during diagnosis and exposure to treatment, which allowed more harmony and openness to enjoy pleasurable sexual relations.

Interviewee: [...] But I think the change has brought peace to enjoy that moment. [...] I have more orgasms than I had before. Many more (Amanda, 51 years, married).

Some of the discourses indicated that the sexual life remained the same as before the breast cancer, good or bad, according to the relationship pattern maintained with the partner.

E: Did you find that the breast cancer could cause a change in the sexual life of the woman?

Interviewee: I'll speak for me. No. (Carolina, 59 years old, married).

Some participants felt that the sexual problems of the partner, for example erectile dysfunction caused by health problems, such as hypertension, or aging, were more relevant than the cancer. In the focus groups there were reports of a decrease in sexual frequency and sexual pleasure, which was attributed to menopause rather than the cancer. This is an important issue because many women are already experiencing a process of transformation of the sexual experience related to aging when they are diagnosed with breast cancer. In these cases, the treatments can accelerate the menopause resulting in the women being unable to distinguish the characteristics of aging from the adverse effects of the treatments, as the agents of changes that interfere in the sexual activity and that could be, in some way, managed by the healthcare professional.

The same issues described by the previous group integrated the reports regarding the perception of a worsening of the sexual life after breast cancer. Some participants indicated that the physical changes caused by the treatments made the sexual life worse than it had been.

Interviewee: [...] Now there is another thing... slowly, carefully [...] there's pain, you say to stop. [...] It changed a lot. We played a lot when we were together. Today it's a very serious thing, a ritual, something strange (Rita, 54, married).

There were also reports of a more distressing sexual experience due to fear of loss of sexual attractiveness and fear of rejection from the partner and statements that revealed complaints about sexual abstinence after the treatment due to the lack of sexual desire of the husband, an idea that appears connected to the lack of virility.

\section{Discussion}

In Brazil, as in most Western societies, there has been a long struggle for the rights of women. There have been major social transformations over the last 40 years in the country, which have allowed greater equality between the sexes ${ }^{(17)}$. However, such transformations are perceived in different ways by the political, public and private spheres. These changes have not been fully assimilated by the Brazilian cultural scenarios, at least with regard to the intimate and private themes. The country has a varied sexual culture, in which greater sexual freedom is observed more for certain social groups than for others ${ }^{(18)}$. The accounts of the participants showed part of this cultural diversity. Being a tropical country, the exposure of the body is intense, particularly in certain places such as in the residence of the participants. Furthermore, there is an overvaluation of female body beauty linked to youth, with the body being considered a capital that can guarantee the woman who personifies the culturally exalted standard a gateway to success in her social, sexual, and loving relationships ${ }^{(19)}$. Thus, the bodily changes caused by the breast cancer treatments may generate anxiety for people who consider such representations to be important. It is considered that the adoption of broad definitions of sexual attractiveness could minimize feelings of exclusion, as this strategy would allow the current reality of a physical appearance altered by the breast cancer treatment to be regulated with culturally valued standards, making the women feel members of their own definitions, while not contemplating the physical attributes of the social ideals.

The set of reports allowed two basic discourses on sexuality interrelated with traditional gender 
relationships to be identified. Such relationships were described as fixed and polarized in one discourse and presented in a diffuse way in another discourse, since the female role is more malleable than that of the male. The discourses on sexuality allow the comprehension that the cultural scenarios include models and rules of social conduct that, although hegemonic, can coexist with other standards, since society and people are constantly changing and participate in a realignment process in which sexual scripts are followed, questioned or modified. Social interactions occurs from the adoption or adaptation of culturally widespread social norms ${ }^{(11)}$. In this respect, non-communication about sexuality or communication truncated by the indirect approach may be related to the discourse on sexuality strongly influenced by the asymmetrical power relationship linked to gender that allows men a wide expression of sexuality and denies that freedom to women, whose sexual life should be regulated and restricted to marriage(10,20-21). Since female sexuality is denied, it should not be a subject of conversation, even among women.

The findings regarding communication with the partner are convergent with other studies that emphasizes the need to establish good communication between the couple so that the sexual and intimate life can be renegotiated after the illness, to take into account the needs and feelings of each person(6). Clear communication between the couple and seeking information and guidance from the healthcare professional can improve the adaptation of the sexual life after breast cancer(22).

There were reports of a worsening of the sexual life related to the effects of the breast cancer treatments, as highlighted in most academic works on the theme ${ }^{(3,7-8)}$. The positive evaluations that some women made about the quality of their sexual lives and the reports about no changes of their sexual lives corroborate other studies that discussed the importance of the perception of support and affection from the partner in the adaptation of the sexual life after cancer breast cancer ${ }^{(22-24)}$. For some authors female sexuality has a greater erotic plasticity than that of the male due to suffering greater pressure from the sociocultural standards of beauty and sexual attractiveness, with a relationship between the dissatisfaction with the bodily appearance and difficulties in the female sexual function that impair their experience of sexuality ${ }^{(25)}$. In this sense, it is considered that the reports of some participants evidence how the concern about being sexually attractive to the partner prevented a satisfactory sexual experience.
This study provides the production of new knowledge, to show how the diversity of reports of women treated for breast cancer can be interpreted in the light of sociocultural concepts about cancer and sexuality, and how the experiences of cancer influenced their relationships with partners and provided different rearrangements in the experience of sexuality. Regarding the possible impact of the knowledge produced by this study for healthcare practices, it can be stated that the results provide support so that healthcare professionals can address sexuality as an important aspect in the care for oncological patients. Care for the psychosocial aspects, in addition to the physical consequences of the treatments, may assist the patient care and alleviate suffering in the sexual experience after cancer $^{(3)}$.

Considering the limitations of this qualitative study, it should be mentioned that it is not possible to infer generalizations regarding the consequences of the treatments on the experience of sexuality of women affected by breast cancer. Another aspect refers to the inclusion of patients attending a breast cancer rehabilitation service as the study participants, as these women had more access to information about the disease and the consequences of the treatments on sexuality than the users of outpatient services.

\section{Final considerations}

This qualitative study aimed to comprehend the psychosocial and cultural repercussions of breast cancer and its treatments on the sexuality of women affected. Sociocultural representations regarding sexuality that circulate in Brazilian society are assimilated in different ways by women. These discourses about sexuality were reflected in the communication regarding topics such as sexual pleasure, adapting the sexual life after the disease, and the changes in the sexual life attributed to aging, with the sexual difficulties of the partner also being addressed. The communication with healthcare professionals related to sexuality was described as prescriptive, with little space for dialogue and reflection.

The diversity of reports obtained in this study show that the experience of sexuality of women treated for breast cancer does not necessarily become worse, even after undergoing the treatments that adversely affect the sexual function. It is important that healthcare professional take into account the complex interaction between cultural, relational, and subjective aspects that is present in the sexual experience after breast cancer, in order to provide better oncological care. 


\section{Acknowledgements}

The Center for Teaching, Research and Assistance in the Rehabilitation of Mastectomized Women, REMA-EERP/USP.

\section{References}

1. World Health Organization. Cancer. Fact sheet $n^{\circ}$ 297. fev. 2012. Geneva; 2012 [acesso 28 fev 2012]. Disponível em: http://www.who.int/mediacentre/ factsheets/fs297/en/print.html

2. Instituto Nacional de Câncer (BR). Estimativa 2012: Incidência de câncer no Brasil. Rio de Janeiro: INCA; 2011. 118 p.

3. Macieira RC, Maluf MF. Sexualidade e câncer. In: Kovacs MJ, Franco MHP, Carvalho VA, editores. Temas em Psico-oncologia. São Paulo: Summus; 2008. p. 303-15.

4. Silva G, Santos MA. Stressors in Breast Cancer PostTreatment: a Qualitative Approach. Rev. Latino-Am. Enfermagem. 2010;18:688-95.

5. Santos DB, Vieira EM. Imagem corporal de mulheres com câncer de mama: uma revisão sistemática da literatura. Ciênc Saúde Coletiva. 2011;16:2511-22.

6. Gilbert E, Ussher JM, Perz J. Renegotiating Sexuality and Intimacy in the Context of Cancer: The Experiences of Carers. Arch Sex Behav. 2010;39(4):998-1009.

7. Cesnik VM, Santos MA. Mastectomia e sexualidade: uma revisão integrativa. Psicol Reflex Crít. 2012; 25:339-49.

8. Barton-Burke M, Gustason CJ. Sexuality in women with cancer. Nurs Clin North Am. 2007;42(4):531-54.

9. Vieira EM, Yoshinari GH Júnior, Souza HCC, Mancini MPM, Perdoná GSC. História reprodutiva e sexual de mulheres tratadas de câncer de mama. Rev Bras Ginecol Obstet. 2013;35:78-83.

10. Villela WV, Arilha M. Sexualidade, Gênero e Direitos Sexuais e Reprodutivos. In: Berquo $E$, editor. Sexo \& Vida- Panorama da Saude Reprodutova no Brasil. Campinas: Editora Unicamp; 2003. p. 95-150.

11. Gagnon J. Uma interpretação do desejo: ensaios sobre o estudo da sexualidade: Editora Garamond; 2006. 12. Biglia N, Moggio G, Peano E, Sgandurra P, Ponzone R, Nappi RE, et al. Effects of Surgical and Adjuvant Therapies for Breast Cancer on Sexuality, Cognitive Functions, and Body Weight. J Sex Med. 2010;7(5):1891-900.

13. Panjari M, Bell RJ, Davis SR. Sexual Function after Breast Cancer. J Sex Med. 2011;8(1):294-302.

14.Giami A, Moulin P, Moreau E. La place de la sexualité dans le travail infirmier : I'érotisation de la relation de soins. Sociol Trav. 2013;55(1):20-38.
15. Resolução 196/96 sobre pesquisa envolvendo seres humanos (BR). Brasilia: Conselho Federal de Saúde; 1996. 16. Denzin NK. The Research Act: A Theoretical Introduction to Sociological Methods: Aldine Transaction; 2009.

17.Cepia-ONU. O progresso das mulheres no Brasil 2003-2010. Rio de Janeiro; 2011. 436 p.

18. Heilborn ML. Corpos na cidade: sedução e sexualidade. In: Velho G, editor. Antropologia urbana: cultura e sociedade no Brasil e em Portugal: Editora Zahar; 1999. p. 93-102.

19.Goldenberg M. O corpo como capital: Estação das Letras; 2010. 200 p.

20.Vieira EM. A medicalização do corpo feminino: Editora Fiocruz; 2002.

21. Giami A. Permanência das representações do gênero em sexologia: as inovações científica e médica comprometidas pelos estereótipos de gênero. Physis. 2007; 17:301-20.

22.Sheppard LA, Ely S. Breast cancer and sexuality. Breast J. 2008;14(2):176-81.

23. Duarte TP, Andrade AN. Enfrentando a mastectomia: análise dos relatos de mulheres mastectomizadas sobre questões ligadas à sexualidade. Estud Psicol. (Natal). 2003;8(1):155-63.

24. Wimberly SR, Carver CS, Laurenceau JP, Harris SD, Antoni $\mathrm{MH}$. Perceived partner reactions to diagnosis and treatment of breast cancer: Impact on psychosocial and psychosexual adjustment. J Consult Clin Psychol. 2005;73(2):300-11.

25. Woertman L, Van Den Brink F. Body Image and Female Sexual Functioning and Behavior: A Review. J Sex Res. 2012;49(2-3):184-211.
Received: Apr. 24 2013

Accepted: Fev. $12^{\text {th }} 2014$ 